\title{
The Semantics of Imperatives within a Theory of Clause Types
}

\author{
Paul Portner \\ Georgetown University
}

\section{Introduction: Clause Types}

Though individual clause types - especially declaratives, interrogatives, and imperatives - have been studied extensively, there is less work on clause type systems. ${ }^{1}$ This is so despite the fact that clause type systems have properties which suggest that they will prove revealing concerning the nature of Universal Grammar. For example, we may ask:

a. Why are some clause types (declaratives, interrogatives, and imperatives) universal?

b. Why are some clause types possible but not universal (e.g., exclamatives and promissives)?

c. Why are some intuitively plausible clause types in fact not attested, and perhaps not possible (e.g., "threatatives" and "warnatives")?

The contrast between imperatives and promissives brings out the issue well. These two types are functionally very similar: An imperative places a requirement on the addressee, while a promissive places a requirement on the speaker. Yet imperatives are apparently universal (and at least extremely common), while promissives are extremely rare. It does not seem easy to give a functional explanation for this contrast, and so in is reasonable to inquire into whether an explanation in terms of syntactic or semantic theory is possible.

Clauses may of course be categorized in a wide variety of ways, and so it is a necessary precondition to the study of clause type systems to have a definition which makes clear which types of types we have in mind. Sadock \& Zwicky (1985) provide a suitable definition. According to them, clause types are universal, form a closed system, and are associated with a specific force. We should understand the property of universality in terms of (1) above; the major types are universal, whereas the others have noteworthy typological properties. Saying that clause types form a closed system is to say that every sentence is a member of one and only one type. This implies, for example, that the indicative mood is not a clause type in the relevant sense, since root declaratives and interrogatives are typically both declarative/interrogative and indicative. The concept of force most frequently invoked, especially in the syntax literature, is that of illocutionary force, but this is not accurate. Illocutionary force is a communicative-intentional concept, so that (2), used in its stereotypical way, has the force of requesting, not asking.

(2) Would you please pass the salt? 
Nevertheless, we want (2) to fall under the clause type of interrogative. Therefore, a better concept for purposes of explicating the concept of clause type is that of sentential force (Chierchia \& McConnell-Ginet 1990) or sentence mood (e.g. Reis 1999).

The general question we'd like to address is: How is the sentential force of a given clause type arrived at? Two main approaches are found in the literature:

1. Clauses are "typed" (i.e. marked as belonging to a certain type) through the presence of some specialized element, often seen as encoding the force of the clause. This element is viewed as residing high in the clausal structure, typically in the CP domain (e.g., Baker 1970, Cheng 1991, Rizzi 1990, 1996, Rivero \& Terzi 1995, Han 1998).

2. Clauses are "typed" through a combination of grammatical properties, as in the construction grammar approach (Michaelis \& Lambrecht 1996, Kathol 2000, Ginzburg \& Sag 2001). For instance, an interrogative in English might be identified as the abstract construction type that can be realized by the presence of a wh operator or subject-auxiliary inversion (cf. Ginzburg \& Sag).

Both of these approaches accept the idea that the type of a clause is formally represented. This is so whether or not a particular theory proposes that force is syntactically encoded. Given that force is in a one-to-one correspondence with type, if something represents the sentence's force, this serves to mark the type; conversely, if something mark the type, this serves to indicate the force. In contrast, we propose that truth-conditional, compositional semantics mediates the form-force pairing (cf. Hausser 1980). That is, atoms of morphosyntax contribute to meaning in a compositional way, but force is not one of the aspects of meaning they contribute. Rather, the result of compositional interpretation is always a traditional semantic object like a proposition or property (along with associated presuppositions and so forth, of course). According to our hypothesis, force is determined only indirectly, on the basis of these meanings.

\section{Imperatives within the Clause Type System}

This paper will focus on imperatives as a case study into the nature of clause type systems. In particular, we aim to answer the following two questions:

1. How do the semantics and pragmatics of imperatives fit together with what we know about declaratives and interrogatives?

2. Why are imperatives, interrogatives, and declaratives the only universal clause types?

Two additional questions concerning the syntax/semantics interface are also of interest:

3. What explains the distinctive properties of the imperative subject? 


\section{What explains the distinctive properties of imperatives' IP/CP syntax?}

Though we will touch on these latter two questions to some extent, space precludes us from discussing the syntax of imperatives in any detail. ${ }^{2}$

In order to answer the first question - how imperatives are to be related to other major clause types - we should begin by reviewing what we know about those other types. It is, of course, commonly assumed that declaratives denote propositions. Since the work of Stalnaker $(1974,1978)$, we understand assertion as being the addition of a proposition to the Common Ground, the set of propositions mutually assumed by the participants in a conversation. The sentential force of declarative clauses is assertion, which is to say that they are conventionally used to add the proposition that they denote to the Common Ground. (The precise nature of this convention is to be explicated further as we go along.)

In parallel to the relationship between declaratives and the Common Ground, Ginzburg (1995a, b) and Roberts (1996) propose that interrogatives are associated with a Question Set. ${ }^{3}$ The elements of the Question Set are interrogative denotations, and so on the simple assumption that interrogatives denote sets of propositions (Hamblin 1973, Karttunen 1977), the Question Set is a set of sets of propositions. The questions in the question set are those which the participants in the conversation mutually agree to try to answer; that is, they represent issues which the conversation will, ideally, resolve. The conventional force of interrogatives, Asking, is then the addition of the set of propositions denoted by the interrogative to the Question Set.

In this context, the natural proposal to make for imperatives is that they are associated with a discourse object which is a set of imperative denotations (cf. Han 1998, Potts 2003, Roberts 2004). As a first, intuitive approximation, we can say that imperatives represent actions which the addressee should take; accordingly, we label this kind of set of imperative denotations a To-Do List. In contrast to the Common Ground and Question Set, which are shared among participants in a conversation, each individual has her own To-Do List. What is shared among participants in a conversation is better modeled as a To-Do List Function, a function which assigns a To-Do List to each participant.

As will be discussed in more detail Section 2, we suggest that imperatives denote properties (Hausser 1980), and so a To-Do List is a set of properties. For example, the imperative (3) denotes something like the property of leaving: ${ }^{4}$

\section{Leave!}

The conventional force of imperatives, what we can call Requiring, is to add the property denoted by the imperative to the addressee's To-Do List. To be more precise, the force of Requiring must be indexed to the addressee, so that Requiring $_{\mathrm{A}}$ is the addition of the imperative's denotation to the To-Do List associated with A by the To-Do List Function.

Distinctions among subtypes of imperatives - orders, requests, permissions, etc. - should not be understood at the level of conversational force. 
That is, they all share the force of Requiring, as they all conventionally add a property to the addressee's To-Do list. Rather, these differences have to do with the pragmatic or sociolinguistic basis for the speaker's attempt to add a property to the addressee's To-Do list. Orders occur when the basis is social authority. Requests occur when no social authority is invoked, and the basis is the speaker's or addressee's benefit. Permissions occur when the property is understood to be one the addressee herself wants on her To-do list.

Table 1 summarizes the preceding discussion:

\begin{tabular}{|l|l|l|l|}
\hline Type & Denotation & Discourse Component & Force \\
\hline Declaratives & proposition $(\mathrm{p})$ & $\begin{array}{l}\text { Common Ground } \\
\text { set of propositions }\end{array}$ & $\begin{array}{l}\text { Assertion } \\
\mathrm{CG} \cup\{\mathrm{p}\}\end{array}$ \\
\hline Interrogatives & $\begin{array}{l}\text { set of } \\
\text { propositions (q) }\end{array}$ & $\begin{array}{l}\text { Question Set } \\
\text { set of sets of } \\
\text { propositions }\end{array}$ & $\begin{array}{l}\text { Asking } \\
\mathrm{QS} \cup\{\mathrm{q}\}\end{array}$ \\
\hline Imperatives & property (P) & $\begin{array}{l}\text { To-Do List Function } \\
\text { function from } \\
\text { individuals to sets of } \\
\text { properties }\end{array}$ & $\begin{array}{l}\text { Requiring } \\
\text { TDL(A) } \cup\{\mathrm{P}\}\end{array}$ \\
\hline
\end{tabular}

Table 1

Given the ideas in Table 1, we can see why the goal of understanding how morphosyntactic form is mapped onto sentential force does not require that force be encoded in syntax. We hypothesize that the following:

(4) The Discourse Context is universally comprised of (at least) three components: the Common Ground, Question Set, and To-Do List Function.

(5) a. The generalized update function $F=$ "take a set of $x$ 's and another $x$, and add the new $\mathrm{x}$ to the set" is universal. (More precisely, $\mathrm{F}=$ $\{<\mathrm{c},<\mathrm{a}, \mathrm{r}>>$ : For some set $\mathrm{X}, \mathrm{c} \in \mathcal{P}(\mathrm{X}) \& \mathrm{a} \in \mathrm{X} \& \mathrm{r}=\mathrm{c} \cup\{\mathrm{a}\}\}$.)

b. No other update function is universal, and $F$ is the preferred update function in the sense that if $\mathrm{F}$ can be used to establish the force of a sentence, it must be. ${ }^{5}$

Given such universal resources, it is to be expected ${ }^{6}$ that every language will have a type of sentence such that $F($ Common Ground, $\|S\|)$ is defined; ${ }^{7}$ such sentences are declaratives. In other words, the sentential force of declaratives can be deduced from the fact that they denote propositions, and thus are suitable for 
being added to the Common Ground by the universal update function $F$. Likewise, it is to be expected that every language will have a sentence type such that $\mathrm{F}(\mathrm{Question}$ Set, $\|\mathrm{S}\|)$ is defined; these are the interrogatives. Finally, it is to be expected that every language will have a sentence type such that $\mathrm{F}$ can use it to affect the To-Do List Function. Imperatives play this role.

An issue we will contend with in more detail in Section 3.2 is whether the universal in (4) is itself explainable in terms of more fundamental considerations, or whether it is simply a primitive fact about the human language faculty. Our contention is that the former possibility is correct: putting aside the Question Set (since interrogatives are not the focus of this paper), it will be argued that the Common Ground and To-Do Lists are related in a tight way, so that a proper understanding of what a To-Do List is can only be offered in light of an understanding of what the Common Ground is, and vice versa. In other words, the Common Ground and To-Do Lists form a package deal - you take either both or neither (and if you take neither your language isn't going to be good for much). Therefore the Common Ground and To-Do List Function are universal.

Returning to the issue of force assignment, in a general sense imperatives fit into the picture correctly: they denote properties, and so are added to the addressee's To-Do List, a set of properties. However, matters are not as simple as with declaratives and interrogatives. This is so because the hypotheses in (4)-(5) are not by themselves enough to predict that every language should have a clause type which is used to affect the addressee's To-Do List in particular, rather than any other individual's To-Do List. The issue is most pointed with regards to the speaker's To-Do List: Why are promissives, which are attested in Korean (Pak 2003, cf. (20) below) and add a property to the speaker's To-Do List, rare, while imperatives, which differ minimally in affecting the addressee's To-Do List, are universal (or at least extremely common)? Though we will not answer this question fully in this paper, we will address it further in Section 4. Our speculation is that the typological contrast between imperatives and promissives is not semantic or pragmatic in nature, but rather based in syntax. ${ }^{8}$

\section{Formal Analysis of Imperatives}

In this section we will discuss the semantics and, especially, the pragmatics of imperatives in more detail.

\subsection{Semantics of Imperatives}

We hypothesize that an imperative denotes a property which can only be true of the addressee. For example, (6) denotes the property in (7), where c represents the context of utterance, $w^{*}$ is the world of evaluation, and we set aside other indices such as temporal ones for simplicity:

(6) Leave! 


$$
\| \text { Leave! } \| \mathrm{W}^{*}, \mathrm{c}=[\lambda \mathrm{w} \lambda \mathrm{x}: \mathrm{x}=\operatorname{addressee}(\mathrm{c}) . \mathrm{x} \text { leaves in } \mathrm{w}]
$$

The condition that the argument $\mathrm{x}$ is the addressee is given as a domain restriction, so that this function returns neither true nor false when applied to individuals other than the addressee. In any world in which the addressee leaves, the addressee is the only individual to have this property; in any world in which the addressee doesn't leave, nobody has this property. Section 4 contains more discussion of how this interpretation is arrived at in a compositional way (see also Portner 2003a, 2004a, b and Zanuttini 2004 for discussion).

Given the semantics in (7), we can explain in more detail how force is assigned to an imperative clause. Since an imperative denotes a property, it is not suitable for being added (by F in (5)a) to the Common Ground or Question Set. ${ }^{9}$ It is suitable for being added to a To-Do List. Since it is a property which can only be true of the addressee, it would not be felicitous to add it to the To-Do List of any individual other than the addressee; no other individual can do what (6) says, and an order isn't felicitous if it's known in advance that it cannot be followed. Therefore, the force of (6) must be to add the property in (7) to the addressee's To-Do List.

The hypothesis that imperatives denote properties can help us understand why (8)a is not a possible imperative:
a. *Mary kiss (you)!
b. (You) be kissed by Mary!

A common idea about imperatives is that they denote propositions and that they contain a "force marker" indicating that this proposition is used to place a requirement on the addressee. Such a view runs into difficulties with the fact that (8)a and (8)b have the same propositional content. It's hard to see, then, why a force marker couldn't combine with either one equally well, thereby creating an imperative. The problem with (8)a could be seen as simply due to a syntactic requirement that the subject of imperatives be second person, but this is doubtful as evidenced by the possibility of third person imperatives like (9)a. Indeed, the very sequence of words in (8)a can be used as an imperative if it is embedded in a contrastive structure, as in (9)b, but notice the resulting sentence implies that Mary is among the set of addressees:

a. Everyone sit down!

b. MARY kiss YOU [pointing] and JOHN kiss YOU [pointing]!

The idea that imperatives denote properties formed by abstracting over the subject argument allows an explanation of the contrast in (8). Whereas a null subject or a pronominal subject like that in (8)b can be abstracted over, yielding the property of being kissed by Mary, the subject of (8)a cannot be. Therefore (8)a cannot be given a proper imperative denotation. In (9)a, what is abstracted over is a covert domain variable for everyone, while in (9)b contrastive focus introduces a 
variable for the set of addressees (something like "Mary, in contrast to the others in set $X$, where $X=$ the set of addressees").

Section 4 will discuss how simple imperatives are assigned the meaning in (7), in particular focusing on the nature of the imperative subject, and will also examine the difficult examples like those in (9) in a bit more detail. At this point, the primary motivation for treating imperatives as denoting properties is the fact that this approach allows the force of imperatives to be derived in the way indicated above. As we turn to the pragmatics of imperatives in Section 3.2, it should be noted that the analysis developed there would be compatible with the idea that imperatives denote propositions, as is ordinarily assumed. Further motivation for their treatment as properties will come in Section 4.

\subsection{Pragmatics of Imperatives}

This section aims to address two issues. The first concerns the nature of To-Do Lists. Like the Common Ground and Question Set, the To-Do Lists are part of a model of how language fits into interaction. But a To-Do List is formally just a set of properties, and so the question arises of how this set is to be understood as helping to model interaction. The second issue was brought up in Section 2, and is related to the first. We have hypothesized that the To-Do List Function, like the Common Ground and Question Set, are universal. In this section, we will examine whether its universality is to be expected given its role in modeling interaction.

The fundamental hypothesis of this section is that the roles of the Common Ground and To-Do Lists are tightly integrated. The Common Ground provides a background of "live possibilities", possible worlds which might be actual as far as the participants in the interaction are concerned. The interaction proceeds against this space of possibilities. An individual's To-Do List then orders the possibilities compatible with the Common Ground, ranking some as preferable to others. The individual's actions are then judged according to the extent to which they tend to make it the case that the actual world is among the higher-ranked possibilities.

Before getting into formal details, some analogies to other topics in semantics should help clarify the relationship between the Common Ground and To-Do List. First we can compare imperative semantics to modal semantics; in terms of Kratzer's (1991) theory of modality, we can relate the Common Ground to the Modal Base, and the To-Do List to the Ordering Source. Consider the deontic modal example (10):

Mary must pay a $\$ 20$ fine.

Example (10) is interpreted with respect to a circumstantial Modal Base representing a set of facts. The facts circumscribe a set of relevant possible worlds (worlds in which Mary received a ticket for illegal parking, let's say). The relevant possible worlds are then ranked according to a deontic Ordering Source 
representing the laws of the place in which she parked. According to these laws, among the worlds compatible with the Modal Base, ones in which she pays the fine are most highly ranked, and on this ground (10) is true.

Another analogy, and one which brings us closer to the particular case of imperatives, concerns the semantics of desire predicates (e.g., Heim 1992, Villalta 2000). Let us consider the example in (11):

Mary wants to visit the Dolomites.

Example (11) is interpreted with respect to a background set of propositions representing Mary's beliefs. These beliefs provide a space of open possibilities, worlds which might be real as far as Mary is concerned. Within this space, Mary's desires rank the various possibilities. Example (11) will be true if her desires rank visiting the Dolomites more highly than the other open possibilities. The analogy to the pragmatics of imperatives should be apparent: Mary's beliefs correspond to the Common Ground, and her desires correspond to the To-Do List.

A third analogy is closely connected to the preceding one, and is revealing as it takes us out of the domain of semantics and into one more relevant to pragmatics. Philosophers such as Stalnaker (1984) and Lewis (1986) have sought to ground possible worlds semantics in a theory of rational action based on an idealized belief-desire psychology. The basic idea is that we judge an agent's actions to be rational to the extent that they will tend to bring it about that the world is as the agent desires, given what the agent believes. As was the case with (11), the beliefs and desires can be modeled in terms of possible worlds, so that the beliefs demarcate a space of live possibilities, and the desires rank those possibilities. Roughly speaking, the agent's actions are rational to the extent that, if undertaken in any of the worlds which are considered live possibilities, they would tend to bring it about that this world becomes maximally highly ranked.

We may think of the Common Ground and To-Do List as being the public, or interactional, counterparts of the individual agent's beliefs and desires. That is, as far as the participants in an interaction go, an agent's actions will be judged rational to the extent that, if undertaken in any world compatible with the Common Ground, they would tend to make this world maximally highly ranked according to that agent's To-Do List. To take a simple example, suppose that it is in the Common Ground that a certain door leads outside. A tells B "Go outside right away!", and B does not object to the order. In that case, if B opens the door, his actions will be judged rational in a straightforward way. If he sits down in a chair and closes his eyes, his actions might be judged irrational. ${ }^{10}$

We can now turn to a formal implementation of these ideas. TDL(i) represents the To-Do List of individual $i$ and CG represents the Common Ground: $^{11}$

Partial Ordering of Worlds:

For any $w_{1}, w_{2} \in \cap C G, w_{1}<i w_{2}$ iff for some $P \in T D L(i), P\left(w_{2}\right)(i)=T$ and $\mathrm{P}\left(\mathrm{w}_{1}\right)(\mathrm{i})=\mathrm{F}$, and for all $\mathrm{Q} \in \mathrm{TDL}(\mathrm{i})$, if $\mathrm{Q}\left(\mathrm{w}_{1}\right)(\mathrm{i})=\mathrm{T}$, then $\mathrm{Q}\left(\mathrm{w}_{2}\right)(\mathrm{i})=\mathrm{T}$. 
Definition (12) defines a partial order $\left(<_{i}\right)$ on the worlds compatible with the Common Ground ( $\cap \mathrm{CG})$. Note that if we have $\mathrm{w}_{1}<_{\mathrm{i}} \mathrm{w}_{2}, \mathrm{w}_{2}$ is the "better" world. With this definition as background, we define the key pragmatic concept:

\section{Agent's commitment}

For any agent $i$, the participants in the conversation mutually agree to deem i's actions rational and cooperative to the extent that those actions in any world $w_{1} \in \cap C G$ tend to make it more likely that there is no $w_{2} \in \cap C G$ such that $\mathrm{w}_{1}<_{\mathrm{i}} \mathrm{w}_{2}$.

According to (12)-(13), to be judged rational an agent must attempt to make as many properties on her To-Do List true as possible. ${ }^{12}$ An alternative way of approaching the interpretation of imperatives might be to say that the agent will be judged rational to the extent that her actions tend to make it the case that the world is one in which all of the properties on her To-Do List are true. That this is not the right way to go can be seen by considering what happens when an individual receives conflicting orders. Such a situation does not lead to every action, or no action, being seen as rational. Rather, it is rational to seek to make as many To-Do List properties true as possible, and this is reflected in the definitions above.

The definitions in (12)-(13) make clear the way in which the Common Ground and To-Do List are tightly integrated. Together they serve to define the relationship between what participants in a conversation say and what they can be expected to do. Since it seems likely that one of the fundamental - if not the fundamental - function of language is to allow us to use words to coordinate our actions, the To-Do List and the Common Ground seem essential to language. This is why the To-Do List Function is universal.

\section{Imperatives and Promissives}

This section focuses on two puzzles left over from preceding sections. One question is why imperatives are typologically so much more prominent than promissives. This difference is surprising given that their semantics and pragmatics are so similar; in terms of the theory presented in this paper, they both denote properties which are added to a To-Do List, the difference being whether it is the speaker's or addressee's To-Do List. (Any other theory of promissives is likely to treat them as quite similar to imperatives in its own terms.)

Another open issue is how the semantics of imperatives in (7) imperatives denote a property which can only be true of the addressee - is compositionally arrived at. We believe that this question is closely related to the previous one; we will suggest that the typological difference between imperatives and promissives has its basis in syntax. Therefore, in this section we will begin by considering the compositional interpretation of imperatives, focusing in particular on the imperative subject. 


\subsection{The Imperative Subject}

We have hypothesized that imperatives denote properties, in particular properties whose argument is restricted to the addressee. There are a couple of ways one could seek to arrive at such a denotation compositionally. One possibility would be that the subject argument of imperatives is never saturated. For example, it could be that the verb in (14) has the meaning in (15)a (leaving out intensionality for the moment). Then, somehow, the domain restriction ' $x=$ addressee(c)' is added to yield (15)b.

(14) Leave!
a. $[\lambda x \cdot x$ leaves $]$
b. $[\lambda x: x=$ addressee $(c) . x$ leaves $]$

An alternative possibility is that the subject of the imperative clause is saturated, but then abstracted over later on. While the first possibility seems plausible for simple imperatives with null subjects, it is difficult (though not impossible) to see how to handle overt subjects in these terms, especially third person referential and quantificational ones like (16)b-c:
a. You be quiet!
b. Everyone sit down!
c. JOHN stand HERE and MARY stand THERE!

Because of examples like those in (16), we analyze the imperative verb as having a fully saturated argument structure. A covert variable-binding operator high in the clausal structure converts the imperative clause into a property-denoting expression. In simple cases like (14) and (16)a, the subject argument is abstracted over. In (16)b-c, the situation is more complex; in (16)b a covert domainvariable for the quantifier is abstracted over, while in (16)c the contrastive focus somehow provides a variable for the operator to bind. The resulting meanings are something like (17)a-c: ${ }^{13}$
a. $[\lambda w \lambda x: x=$ addressee $(c) . x$ is quiet $]$
b. $[\lambda w \lambda x: x=$ addressee $(c) .[\forall y: y \in x \cdot y$ sits down $]]$
c. $[\lambda w \lambda x: x=$ addressee $(\mathrm{c})$. John $\in \mathrm{x} \&$ John stands here \& Mary $\in \mathrm{x} \&$ Mary stands there]

If this way of looking at the syntax-semantics interface of imperatives is correct, the imperative subject is unique among root subjects in that it must either be or be associated with a variable which is bound. ${ }^{14}$ This raises two additional questions: First, what is the nature of this variable? And second, what is the formal status of the requirement that imperative subjects be or be associated with it? This paper will only address the first question. 
We propose that the variable - referred to loosely as "the imperative subject" in what follows - is an addressee-oriented logophoric pronoun. Such a suggestion allows us to make sense of the properties of the imperative subject. Within the recent formal analyses of logophoricity of Schlenker $(1999,2003)$ and von Stechow (2002), logophoric pronouns are pronominal elements always bound by covert variable-binders; they always have indexical meaning like 'is the speaker of context c'. In both of these ways, they are like the imperative subject. Of course the special property of logophoric elements, that their indexical meaning does not locate their reference in the actual speech situation, but rather in a linguistically introduced speech situation, is not typically reproduced with imperatives, because they cannot be embedded. However, in Korean we do find embedded imperatives, and as expected their subject is interpreted with respect to the reported speech act (from Pak 2003):

$$
\begin{aligned}
& \text { Emma-ka mek-u-la mal-ha-si-ess-ta } \\
& \text { Mom-NOM eat-IMV-Comp say-do-SH-PST-DEC } \\
& \text { 'Mom told (me) to eat.' }
\end{aligned}
$$

Crucially, (18) does not mean 'Mom told you to eat', but rather 'Mom told the person she was addressing to eat'. This shows that the subject of an imperative, while addressee-oriented, is not tied to the actual speech context in the way that an ordinary indexical like you is.

The idea that the imperative subject is a logophoric pronoun may also contribute to an explanation for why English imperatives may have a null subject. This fact is surprising, given that Standard English root clauses typically do not allow null subjects. However, if the imperative subject is in fact not an ordinary pronoun, but rather a logophoric element, it is less surprising. The logophoric pronoun is a distinct lexical item from ordinary pronouns, and so there's no reason it should not happen to have null phonological form.

\subsection{The Person Features of the Imperative Subject}

In light of the analysis of imperative subjects, we are now in a position to say more precisely what distinguishes imperatives from closely related clause types like promissives. Whereas the imperative subject adds the descriptive content is the addressee' to the sentence's meaning, the subject of a promissive adds the descriptive content 'is the speaker'. Another closely related type, hortatives, adds the content 'is the speaker and addressee'. We see all three types exemplified in Korean (from Pak 2003):

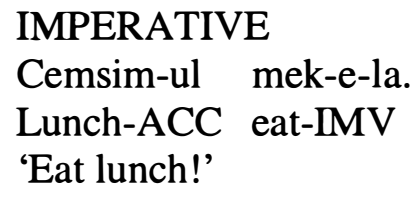


(20)

PROMISSIVE

Nay-ka nayil cemsim-ul sa-ma.

I-NOM tomorrow lunch-ACC buy-PRM

'I will buy you lunch tomorrow.'

\author{
HORTATIVE \\ Icey cemsim-ul mek-ca. \\ Now lunch-ACC eat-EXH \\ 'Now, let us eat lunch.'
}

Another revealing language is Sanskrit, which has a full person paradigm for imperatives. First person singular imperatives seem to be interpreted as promises (from Mauck et al. 2004):

$$
\begin{aligned}
& \text { AavyuSam jaagrtaat aham. } \\
& \text { daybreak watch-IMP.1s I } \\
& \text { 'I will watch until daybreak' (AV 144) }
\end{aligned}
$$

One might suggest that imperatives are universal while promissives are not because the kind of subject needed for imperatives, the addressee-oriented logophor, is universal, while the kind needed for promissives, the speakeroriented logophor, is not. This solution seems unlikely, however, because speaker-oriented logophors are generally more common than addressee-oriented ones. A more promising possibility is to focus on the operator which binds this element, abstracting over it to make the clause denote a property. Perhaps Universal Grammar provides an operator which can bind an addressee-oriented logophoric element. This operator allows the generation of properties whose argument is restricted to the addressee, i.e. imperatives. According to this way of thinking, a parallel operator for binding the speaker-oriented logophoric element is present in Korean, but it is not universal. ${ }^{15}$

The idea that imperative clauses contain a special operator might receive some syntactic support from the well-known fact that imperative verbs are often in a higher position than declarative verbs. For example, the Italian imperative (23) has the verb to the left of the clitic $t i$, whereas in declaratives it would follow:

Siediti!

Sit.IMP-refl.2sg

'Sit!'

Syntactic accounts often account for the position of the verb by postulating a force feature in the CP domain which drives verb movement. While we are skeptical of a force feature for reasons mentioned above, a similar explanation can be given in terms of the variable binding operator. We speculate that this operator resides high in the clausal structure and triggers verb movement in many languages. ${ }^{16}$ 


\section{Conclusion}

This paper has tried to accomplish two things:

1. It has aimed to present some general issues relevant to the study of clause type systems, and to outline a framework which makes sense for thinking about these issues. Clause type systems have noteworthy typological properties, and in particular we need to explain why some types are universal, some are possible, and some are unattested and perhaps impossible. We have proposed that the universal types are each associated with a universal component of the discourse context (the Common Ground, Question Set, and To-Do List Function). The universal procedure for updating these components is simply to add a semantic object of the right type to one of them. All of this is just a generalization of Stalnaker's original ideas about the Common Ground to the other universal clause types.

2. In the context of this framework, the paper has made some specific hypotheses about the syntactic, semantic, and pragmatic analysis of imperatives. Imperatives denote properties which can only be true of the addressee, and this allows for a pragmatic derivation of their force which dispenses with the need for a "force marker". The force of imperatives is to add a property to the To-Do List of the addressee. Through the use of techniques familiar from modal semantics and the semantics of desire predicates, a To-Do List is used to rank the possible worlds compatible with the Common Ground. The Common Ground in combination with the ranking generated by the To-Do List provides a model for the relationship between what people say and what they can be expected to do as rational agents.

There are a number of open problems, and the most significant of these have to do with the nature of the imperative subject. At one level, we do not understand fully the syntactic or semantic nature of this element; this paper has suggested that it might be an addressee-oriented logophoric pronoun. More fundamentally, we do not understand why this element - whatever it is - is universal and how it becomes associated with the other morphosyntactic properties of imperatives. For example, we do not understand why a null subject is impossible in Standard English root sentences unless the verb has the bare imperative form. This point makes clear the fact that a complete understanding of the semantics and pragmatics of imperatives is not possible without a detailed understanding of their syntax as well. 


\section{Endnotes}

*This paper is part of a collaborative project with Raffaella Zanuttini supported by NSF grant BCS-0234278, 'Clause Types: Form and Force in Grammatical Theory'. We especially thank Miok Pak and Simon Mauck for their contributions. We have received helpful feedback from audiences at ZAS in Berlin, the University of Padua, Northwestern University, Stanford University, and SALT 14.

${ }^{1}$ An important paper which sets up many of the important issues is Sadock \& Zwicky (1985). Recent work which addresses the syntax/semantics/ pragmatics interface in a way similar to the present approach is Ginzburg \& Sag (2001) and Roberts (2004); cf. Hausser (1980), Zanuttini \& Portner (2003), Potts (2003).

${ }^{2}$ Zanuttini (2004) contains relevant discussion.

${ }^{3}$ According to some authors, instead of a simple set, we have a more structured object such as a Question Under Discussion Stack (Ginzburg). This difference is not relevant to us here.

${ }^{4}$ This is not quite accurate, but it is sufficient for present purposes. We will give a more precise characterization in Section 3.

${ }^{5}$ The subtleties of (5)b are not of direct concern here, but they become relevant when we think about such minor clause types as exclamatives. Zanuttini \& Portner (2003) argue that exclamatives denote sets of propositions, like interrogatives. However, they are also associated with a factive presupposition which makes them unsuitable for addition to the Question Set. Therefore, another update function (what we call Widening) is employed.

${ }^{6}$ It's not logically required, however. It's logically possible that a language would leave a discourse component unused. More realistically, it's possible that a language would only have the means for updating a particular discourse component through indirect speech acts; for example, one could lack imperatives and update To-Do Lists through interrogatives like Can you pass the salt? However, given that the morphosyntactic resources for making the major clause types are probably universal, it's not surprising that every language would have a direct means of updating each discourse component.

${ }^{7}$ I use $\|\mathrm{S}\|$ here for the denotation of S, and I leave parameters of interpretation out because it's not relevant exactly what the parameters of interpretation are.

${ }^{8}$ The only plausible functional explanation I can think of involves children's conceptual development during language acquisition. Perhaps at the point when the grammatical resources to affect the To-Do List become available, children can understand what it is to affect someone else's To-Do List, but not what it is to affect their own. This idea represents pure speculation, however.

${ }^{9}$ Thanks to Manfred Krifka (p.c.) for suggesting this pragmatic reasoning.

${ }^{10}$ In more complex cases, we can see that a principle of charity is operative in judging agents' actions. Suppose that there were two doors, one leading outside and another opening into a bathroom. If $B$ were to open the second door, his actions might be judged irrational, but more likely A would assume that B 
understood the temporal semantics of Go outside right away! to allow for a brief bathroom break. This type of charity principle is typical in pragmatic reasoning, as seen in the flouting of Gricean maxims. As is well known, when an utterance apparently violates a maxim, interlocutors typically reinterpret it via implicature so as to bring in into conformity with the maxim. Maxims are never really violated except in truly pathological cases. Likewise, it seems to me that an agent's actions, measured against the To-Do List, are not often going to be judged irrational. Rather, rationality is an assumption onto which interlocutors hold pretty firmly, reinterpreting other aspects of the situation if necessary.

${ }^{11}$ One issue not discussed here is the status of conditional imperatives like (i):

(i) If you see Mary, come home right away!

The force of this sentence is to place the main imperative clause's property (come home right away) onto the addressee's To-Do List only once the if clause (you see Mary) is true. What is difficult is to find of way of implementing this which fits with the semantics of conditionals generally. While I don't have a solution, I note that (i) may be related to relevance conditionals (Austin 1961, Iatridou 1991, sometimes called speech act conditionals among other things) like (ii):

(ii) If you know about gardening, where would be a good place to plant the roses?

12 If two properties $\mathrm{P}$ and $\mathrm{Q}$ on i's To-Do List are incompatible, worlds in which $\mathrm{i}$ has $\mathrm{P}$ and worlds in which $\mathrm{i}$ has $\mathrm{Q}$ will actually not be commensurable. But if $\mathrm{i}$ can have both $\mathrm{P}$ and $\mathrm{Q}$, then worlds in which he has both will be more highly ranked than worlds in which he has only one. Because of space, I must leave the detailed implications of the definitions to the reader.

${ }^{13}$ Note that (16)c is only possible on an contrastive interpretation of John and Mary. Therefore, the meaning in (17)c is very approximate, and this example's correct analysis must make use of a realistic semantics for focus.

${ }^{14}$ Control infinitives have a similar property, of course; their subject, PRO, must be bound. This similarity is probably not accidental, but it's difficult to know exactly what to make of it at this point.

${ }^{15}$ Notice that, according to the theory of Schlenker $(1999,2003)$ and von Stechow (2002), regular logophors are bound by operators introduced by propositional attitude verbs. This mechanism is certainly not available in all languages. The imperative operator is introduced in root clauses, without a licensor like an attitude verb.

16 The syntactic issues here are complex, and this paper only offers a hint as to how we might approach them. One important problem is that not all imperatives show the same position of the verb, even within a single language. For example, negative second person singular imperatives in Italian, which employ the infinitive for their verb form, allow both verb-clitic and clitic-verb order: 
This kind of data is at least as problematical for theories which invoke a force marker as it is for our account. See Portner \& Zanuttini (2003) for discussion.

\section{References}

Austin, J.L. 1961. 'Ifs and Cans', in Philosophical Papers. Oxford: Oxford University Press, 153-180.

Baker, C. L. 1970. Notes on the description of English questions, Foundations of Language 6, 197-219.

Cheng, L. 1991. On the Typology of wh-questions. PhD Thesis, MIT, Cambridge.

Chierchia, G. and S. McConnell-Ginet. 1990. Meaning and Grammar: An Introduction to Semantics. Cambridge, MA: MIT Press.

Ginzburg, J. 1995a. Resolving Questions, Part I. Linguistics and Philosophy $18.5,459-527$.

Ginzburg, J. 1995b. Resolving Questions, Part II. Linguistics and Philosophy 18.6, 567-609.

Ginzburg, J. and I. Sag. 2001. Interrogative Investigations: The Form, Meaning, and Use of English Interrogatives. Stanford: CSLI.

Hamblin, C. 1973. Questions in Montague English. Foundations of Language: $10,41-53$.

Han, C.H. 1998. The structure and interpretation of imperatives: mood and force in Universal Grammar. PhD dissertation, University of Pennsylvania.

Hausser, R. 1980. Surface Compositionality and the Semantics of Mood. In J. Searle, F. Kiefer, \& M. Bierwisch, eds., Speech Act Theory and Pragmatics. Dordrecht \& Boston: D. Reidel, 71-95.

Heim, I. 1992. Presupposition projection and the semantics of attitude verbs. Journal of Semantics 9:183-221.

Iatridou, S. 1991. Topics in Conditionals, PhD dissertation, MIT, Cambridge, MA.

Karttunen, L. 1977. Syntax and semantics of questions. Linguistics and Philosophy 1, 3-44.

Kathol, A. 2000. Linear Syntax. Oxford and New York: Oxford University Press.

Kratzer, A. 1991. The Notional Category of Modality, in H.J. Eikmeyer and H. Reiser, eds., Worlds, Words, and Contexts: New Approaches in Word Semantics. Berlin: Walter de Gruyter, 38-74.

Lewis, D. 1986. On the Plurality of Worlds. Oxford and New York: Blackwell. 
Mauck, S., M. Pak, P. Portner, \& R. Zanuttini. 2004. Clause Typing in Imperatives: A Cross-Linguistic Perspective. Talk delivered at the Georgetown University Round Table, Washington. March 26-29, 2004. (Handout available at www.georgetown.edu/faculty/portnerp/nsfsite/ nsfframeset.htm.)

Michaelis , L. A. and K. Lambrecht. 1996. Toward a construction-based theory of language function: The case of nominal extraposition. Language 72.2, 215-247.

Pak, M. 2003. Sentence Types in Korean. Ms., Georgetown University. Available at http://www.georgetown.edu/faculty/portnerp/nsfsite/ nsfframeset.htm.

Platzack, Christer and Inger Rosengren. 1998. On the subject of imperatives: A minimalist account of the imperative clause, The Journal of Comparative Germanic Linguisitics 1, 177-224.

Portner, P. 2003a. The meaning and force of imperatives. Talk delivered at ESSLI 2003 Workshop on Conditional and Unconditional Modality, Vienna. (Handout available at www.georgetown.edu/faculty/portnerp/ nsfsite/nsfframeset.htm.)

Portner, P. 2003b. The Semantics of Mood, in Lisa Cheng \& Rint Sybesma, eds., The Second Glot International State-of-the-Article Book, Berlin and New York: Mouton de Gruyter.

Portner, P. 2004a. What can we learn about information structure from Imperatives? The lack of specific indefinites. Talk delivered at the Workshop on Information Structure and Grammar, Tübingen, Feb 1-2, 2004. (Handout available at www.georgetown.edu/faculty/portnerp/ nsf site/nsfframeset.htm.)

Portner, P. 2004b. Vocatives, Topics, and Imperatives. Talk delivered at the IMS Workshop on Information Structure, Bad Teinach, Germany, July 1618, 2004. (Handout available at www.georgetown.edu/faculty/portnerp/ nsf site/nsfframeset.htm.)

Portner, P. and K. Yabushita. 2002. Specific Indefinites and the Information Structure Theory of Topics. Journal of Semantics 18.3.

Portner, P. and R. Zanuttini. 2000. The Characterization of Exclamative Clauses in Paduan, Language 76.1: 123-32.

Portner, P. \& R. Zanuttini. 2002. "Form and Force in Grammatical Theory", presented at the workshop on The Syntax-Semantics Interface in the CP Domain, Zentrum für Allgemeine Sprachwissenschaft, Berlin, March 7, 2002.

Portner, P. and R. Zanuttini. 2003. Decomposing Imperatives. Talk delivered at the IX Giornata di Dialettologia, Padova, June 26, 2003. (Handout available at www.georgetown.edu/faculty/portnerp/nsfsite/ nsfframeset.htm.)

Potts, C. 2003. Keeping world and will apart: A discourse-based semantics for imperatives. Talk delivered at the NYU Syntax/Semantics Lecture Series, October 17, 2003. (Handout available at http://www-unix.oit.umass.edu/ \%7Epotts/.) 
Reis, M. 1999. On sentence types in German: An enquiry into the relationship between grammar and pragmatics. IJGLSA 4(2):195-236.

Rivero, M.L. and A. Terzi. 1995. Imperatives, V-movement and logical mood. Journal of Linguistics, 31, 301-322.

Rizzi, L. 1990. Speculations on verb-second. In Mascaró, J. and M. Nespor, eds., Grammar in Progress: GLOW Essays for Henk van Riemsdijk. . Foris, Dordrecht, 137-152.

Rizzi, L. 1996. Residual Verb Second and the Wh-Criterion. In Belletti, A. and L. Rizzi, eds., Parameters and Functional Heads: Essays in Comparative Syntax. New York \& Oxford: Oxford University Press.

Roberts, C. 1996. Information structure in discourse: Towards an integrated formal theory of pragmatics. In Papers in Semantics, OSU Working Papers in Linguistics, Vol 49. Columbus: Department of Linguistics, the Ohio State University.

Roberts, C. 2004. Context in Dynamic Interpretation, in Laurence R. Horn \& Gregory Ward, eds., The Handbook of Pragmatics. Oxford \& Malden, MA: Blackwell, 197-220.

Sadock, J. M. and A. Zwicky. 1985. Speech act distinctions in syntax. In Shopen, T., ed., Language Typology and Syntactic Description. Cambridge: Cambridge University Press, 155-196.

Schlenker, Philippe. 1999. Propositional Attitudes and Indexicality: A CrossCategorial Approach, MIT Ph.D. Dissertation.

Schlenker, Philippe. 2003. A Plea for Monsters, Linguistics and Philosophy 26.1, 29-120.

Stalnaker, R. 1974. Pragmatic Presupposition, in M. Munitz and P. Unger, eds., Semantics and Philosophy, New York: New York University Press, 197213.

Stalnaker, R. 1978. Assertion, Syntax and Semantics 9, 315-332.

Stalnaker, R. 1984. Inquiry. Cambridge, MA: MIT Press.

von Stechow, A. 2002. Feature Deletion under Semantic Binding: Tense, Person, and Mood under Verbal Quantifiers. Talk delivered at the annual meeting of the North East Linguistic Society, November 2002. Ms., Tübingen. (Handout available at vivaldi.sfs.nphil.uni-tuebingen.de/ arnim10/ Aufsaetze/index.html.)

Villalta, E. 2000. Spanish Subjunctive Clauses Require Ordered Alternatives. In Brendan Jackson \& Tanya Matthews (eds.), Proceedings of SALT X.

Zanuttini, R. 2003. Imperative and Clause Types. Talk delivered at the North American Syntax Conference, May 2-4, 2003. (Handout available at www.georgetown.edu/faculty/portnerp/nsfsite/nsfframeset.htm.)

Zanuttini, R. \& P. Portner. 2003. Exclamative Clauses: At the Syntax-Semantics Interface. Language 79.1: 39-81.

Zanuttini, R. 2004. Understanding the restrictions on imperative subjects. Talk delivered at the X Giornata di Dialettologia, University of Padua, June 24, 2004. (Handout available at www.georgetown.edu/faculty/portnerp/ nsf site/nsfframeset.htm.) 